\title{
Surgical repair of massive dilatation of the right atrium with tricuspid regurgitation
}

\author{
Masaho Okada ${ }^{*}$, Hirotaka Watanuki, Kayo Sugiyama, Yasuhiro Futamura and Katsuhiko Matsuyama
}

\begin{abstract}
Background: Massive dilatation of the right atrium with tricuspid regurgitation is frequently diagnosed by accidental recognition of an enlarged cardiac silhouette during routine chest radiography. Although some patients are asymptomatic, enlargement of the right atrium can cause secondary tricuspid regurgitation due to dilatation of the tricuspid annulus, associated with arrhythmias and thrombus formation leading to pulmonary embolism, stroke, and, rarely, sudden death due to left ventricular compression.

Case presentation: A 76-year-old woman was followed up due to atrial fibrillation and tricuspid regurgitation for 8 years. A follow-up echocardiogram showed progressive dilatation of the right atrium. Because of the development of shortness of breath, right atrial plication and tricuspid valve repair were performed. Tricuspid annuloplasty was performed on the beating heart with the use of a 28-mm Carpentier-Edwards Physio tricuspid annuloplasty ring. Plication of the enlarged right atrium was performed at the interatrial septum, the free right atrium wall including the appendage, and the space between the inferior vena cava and the tricuspid ring. Closure of the left atrial appendage was performed from outside to prevent left atrial thrombus formation. Postoperative Xray and computed tomography showed reduced cardiac silhouette and right atrial volume. The patient was discharged uneventfully and returned for follow-up visits with improved symptoms.

Conclusions: An adult case of massive dilatation of the right atrium of unknown etiology is reported. The patient's symptoms were relieved by our operative procedure.

Keywords: Massive dilatation of right atrium, Atrial fibrillation, Right atrial plication, Tricuspid valve repair, Tricuspid annular plane systolic excursion
\end{abstract}

\section{Background}

Massive dilatation of the right atrium (RA) with tricuspid regurgitation (TR) is frequently diagnosed by accidental recognition of an enlarged cardiac silhouette during routine chest radiography. Although some patients are asymptomatic, TR is associated with arrhythmias and thrombus formation leading to pulmonary embolism, stroke, and, rarely, sudden death due to left ventricular (LV) compression [1]. TR may rarely cause massive dilatation of the RA. Here we report a surgical case of massive dilatation of the RA with severe TR.

\footnotetext{
* Correspondence: okmasaho123@gmail.com

Department of Cardiac Surgery, Aichi Medical University, 1-1 Yazakokarimata, Nagakute, Aichi, Japan
}

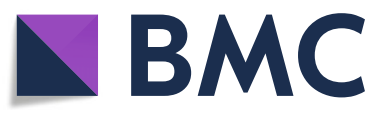

(c) The Author(s). 2018 Open Access This article is distributed under the terms of the Creative Commons Attribution 4.0 International License (http://creativecommons.org/licenses/by/4.0/), which permits unrestricted use, distribution, and

reproduction in any medium, provided you give appropriate credit to the original author(s) and the source, provide a link to the Creative Commons license, and indicate if changes were made. The Creative Commons Public Domain Dedication waiver (http://creativecommons.org/publicdomain/zero/1.0/) applies to the data made available in this article, unless otherwise stated.

\section{Case presentation}

A 76-year-old woman had an 8-year history of atrial fibrillation (AF) and severe TR. Her history included mild hypothyroidism and right upper lobectomy for lung carcinoma 11 years previously. For 2 years, she had complained of shortness of breath when lying in the left lateral decubitus position. She had felt dyspnea after mild exercise for 9 months. Recently, she had a sense of abdominal fullness. Although administration of diuretics was started, her symptoms did not completely improve, and she was referred to our department for surgical treatment. The follow-up chest X-ray showed a gradually protruding right-side shadow of the cardiac silhouette, and the cardiothoracic ratio on the chest X-ray reached $88 \%$ (Fig. 1a). The electrocardiogram showed AF with low fibrillatory wave amplitude. Echocardiography showed an enlarged right ventricular (RV) cavity and mild 


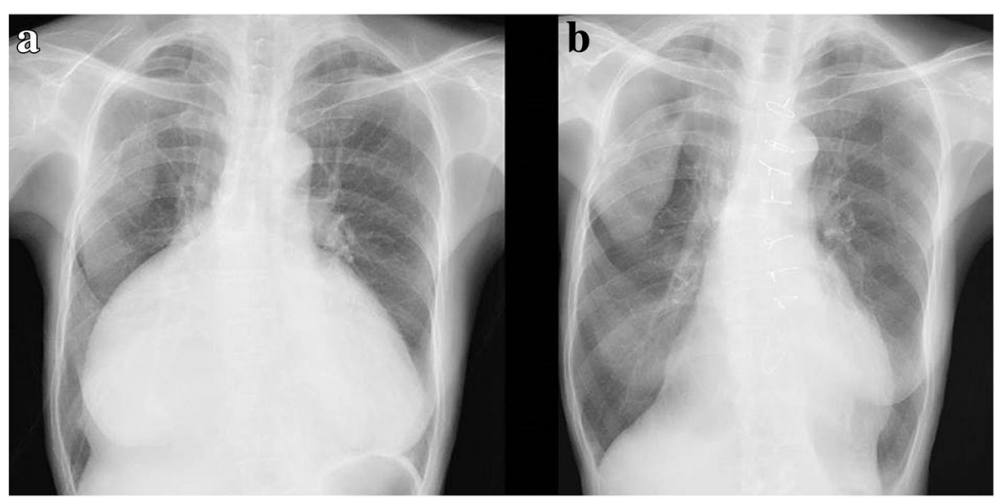

Fig. 1 a Chest X-ray at preoperative examination showed severe enlargement of the heart, with a cardiothoracic ratio of $88 \%$. b Postoperative chest $X$ - ray showed reduced right-side shadow of the cardiac silhouette

paradoxical motion of the ventricular septum. The tricuspid valve had no findings of an organic and constructive abnormality, with no severe tethering. The annular size of the tricuspid valve was $50 \mathrm{~mm}$, and the tricuspid annular plane systolic excursion was $21 \mathrm{~mm}$ (Table 1). Repeated preoperative cardiac catheterization showed slightly elevated wedge pressure with mild pulmonary hypertension, although LV function was preserved with a cardiac index of 4.0 (Table 2). There was no L-R shunt disease. Computed tomography (CT) findings showed that the maximum size of the RA reached $121 \mathrm{~mm}$ (Fig. 2a). The change in dimension of the RA by $\mathrm{CT}$ showed that the size of the RA increased with time (Fig. 3). Blood tests showed no liver dysfunction.

Surgery was performed via median sternotomy. The pericardium was extremely thin on the RA side without any defect. There was no adherence in the pericardial cavity. Cardiopulmonary bypass was established by ascending aorta cannulation with bicaval drainage. The RA was extremely thin and the tricuspid valve annulus was enlarged, with a diameter of $55 \mathrm{~mm}$, but there was no tricuspid structural abnormality. Tricuspid annuloplasty was performed on the beating heart using a 28-mm Carpentier-Edwards Physio tricuspid annuloplasty ring (Edwards Lifesciences, Irvine, CA, USA). Plication of the enlarged RA was performed, mainly at the interatrial septum, the free RA wall, including the appendage, and the space between the inferior vena cava and the tricuspid ring, in addition to the free RA wall, including the appendage (Fig. 4a, b). Additionally, closure of the left atrial appendage from the outside was performed to prevent left atrial thrombus formation. All procedures were performed on the beating heart. The postoperative course was uneventful. The pathological findings of the RA wall demonstrated thinning of the myocardium, inflammatory cell infiltrate, and few cardiomyocytes (Figs. 5a-b, 6). Postoperative $\mathrm{X}$-ray and $\mathrm{CT}$ showed reduced cardiac silhouette and RA volume (Figs. 1b, 2b). Postoperative echocardiography showed an ejection fraction of $58 \%$ and mild TR with a pressure gradient of $29 \mathrm{mmHg}$ (Table 1). The postoperative value of tricuspid annular plane

Table 1 Preoperative and postoperative echocardiography findings

\begin{tabular}{|c|c|c|c|c|c|c|c|c|}
\hline \multirow[t]{2}{*}{ Measurement } & \multicolumn{8}{|c|}{ Years before presentation } \\
\hline & 6 & 4 & 3 & 2 & 1.5 & 0.5 & Pre-ope & Post-ope \\
\hline LVDd (mm) & 37.1 & 39.5 & 36.6 & 40.4 & 38.8 & 43.2 & 37.6 & 42.4 \\
\hline LVDs (mm) & 25.4 & 29.3 & 25.2 & 23.1 & 28.3 & 29.9 & 21.9 & 29.7 \\
\hline LVEF (\%) & 60.5 & 51.4 & 59.7 & 74.5 & 53.5 & 58.7 & 73.5 & 57.5 \\
\hline $\mathrm{LAD}(\mathrm{mm})$ & 36 & 34.9 & 40.3 & 44.8 & 33.9 & 40.4 & 38.9 & 43.3 \\
\hline $\mathrm{RA}(\mathrm{mm})$ & 81 & 91 & 86 & 94.6 & 120 & 96.6 & 109 & 33.5 \\
\hline TAPSE (mm) & 19.9 & 19.2 & 23.7 & 22 & 14.8 & 17.7 & 21.1 & 11.2 \\
\hline IVC (mm) & 21.2 & - & 19.8 & 26.5 & 20.2 & 24.8 & 26 & 16.1 \\
\hline TR grade & Severe & Severe & Severe & Severe & Severe & Severe & Severe & Mild \\
\hline
\end{tabular}

Pre-ope preoperative, Post-ope postoperative, LVDd left ventricular end-diastolic dimension, LVDs left ventricular end-systolic dimension, LVEF left ventricular ejection fraction, $L A D$ left atrial dimension, $R A$ right atrium, TAPSE tricuspid annular plane systolic excursion, IVC inferior vena cava, TR tricuspid regurgitation 
Table 2 Cardiac catheterization analysis

\begin{tabular}{lll}
\hline Measurement & \multicolumn{2}{l}{ Years before presentation } \\
\cline { 2 - 3 } & 4 years & Pre-ope \\
\hline RA mean pressure $(\mathrm{mmHg})$ & 5 & 9 \\
RV systolic pressure $(\mathrm{mmHg})$ & 16 & 27 \\
RV diastolic pressure $(\mathrm{mmHg})$ & 3 & 3 \\
PA systolic pressure $(\mathrm{mmHg})$ & 21 & 31 \\
PA diastolic pressure $(\mathrm{mmHg})$ & 12 & 17 \\
PCWP (mmHg) & 6 & 13 \\
Systemic mean artery pressure $(\mathrm{mmHg})$ & 83 & 87 \\
Cardiac index $\left(\mathrm{I}\right.$ min $\left.^{-1} \mathrm{~m}^{-2}\right)$ & 4.42 & 4.02 \\
\hline
\end{tabular}

$R A$ right atrium, $R V$ right ventricle, $P A$ pulmonary artery, $P C W P$ pulmonary capillary wedge pressure

systolic excursion (TAPSE) decreased after the operation. However, the patient's symptoms were completely resolved, and she was discharged 3 weeks after surgery. The patient is doing well 2 years after surgery.

\section{Discussion}

The pathophysiology of dilated RA is occasionally combined with long-standing AF and severe TR. The etiology of the massive RA dilatation in our patient was unknown. The RA pressure in our patient was less than $10 \mathrm{mmHg}$. The pathological findings include thinning RA wall and few cardiomyocytes, and suggest that the etiology was the original weakness and the acquired degenerative process of the RA. Reported symptoms of enlarged RA include dyspnea, palpitations, chest pain, right heart failure, syncope, and fatigue. However, half of patients with enlarged RA are asymptomatic at the time of diagnosis [1-3].

The approach to treatment of isolated severe TR with dilatation of the RA is controversial. Surgical treatment is recommended in the presence of arrhythmias, congestive heart failure, or LV compression, which may cause sudden death [1]. In the majority of cases, asymptomatic patients can be treated conservatively. The

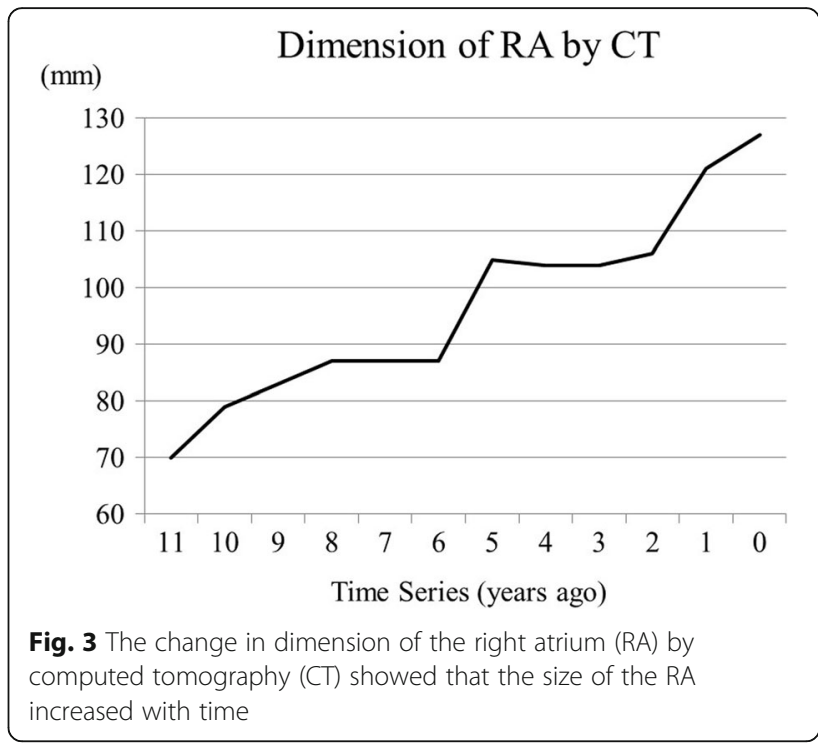

operative indications for TR are mainly related to the presence of symptoms and RV function. According to the guidelines, tricuspid valve (TV) surgery is indicated for symptomatic patients with primary TR unless there is severe RV dysfunction [4]. In our patient, surgery was indicated due to progressive dilatation of the RA, a sign of LV compression, the presence of symptoms, and less severe RV dysfunction.

On the other hand, TV surgery for asymptomatic patients with progressive RV dysfunction is controversial. RV function is a critical component of overall cardiac function, with prognostic value for predicting symptomatic limitations and outcome, although it is difficult to assess RV function because of the complex geometry of the right ventricle. TAPSE has been proposed as a simple and reproducible parameter for the evaluation of RV function and is recommended in the recent guidelines for echocardiographic quantification of RV function, which show that values less than $16 \mathrm{~mm}$ indicate RV systolic dysfunction [5]. TAPSE

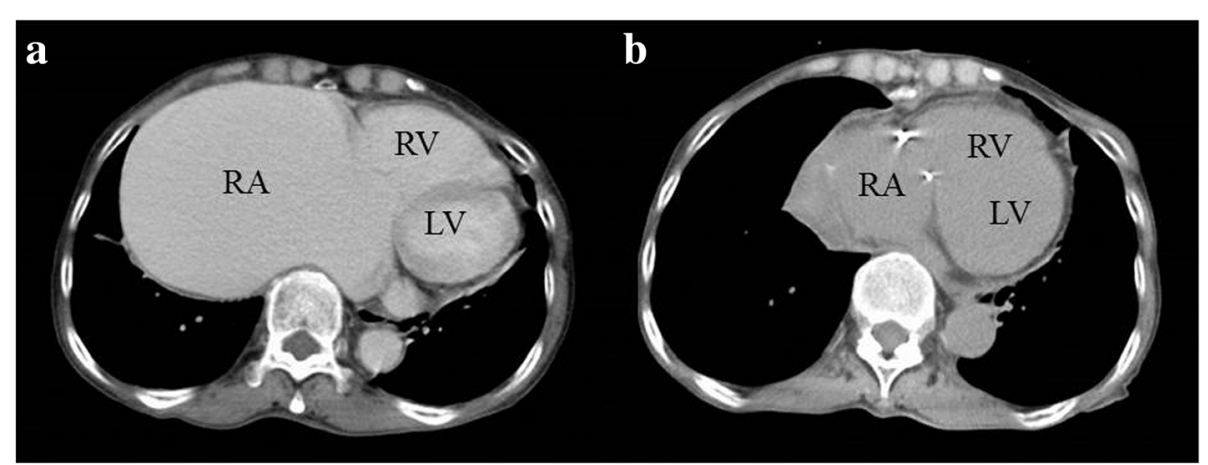

Fig. 2 a Computed tomography (CT) findings showed that the size of the RA increased gradually up to $121 \mathrm{~mm} 1$ year previously. $\mathbf{b}$ Postoperative CT scan showed reduction of the RA. LV, left ventricle; RA, right atrium; RV, right ventricle 

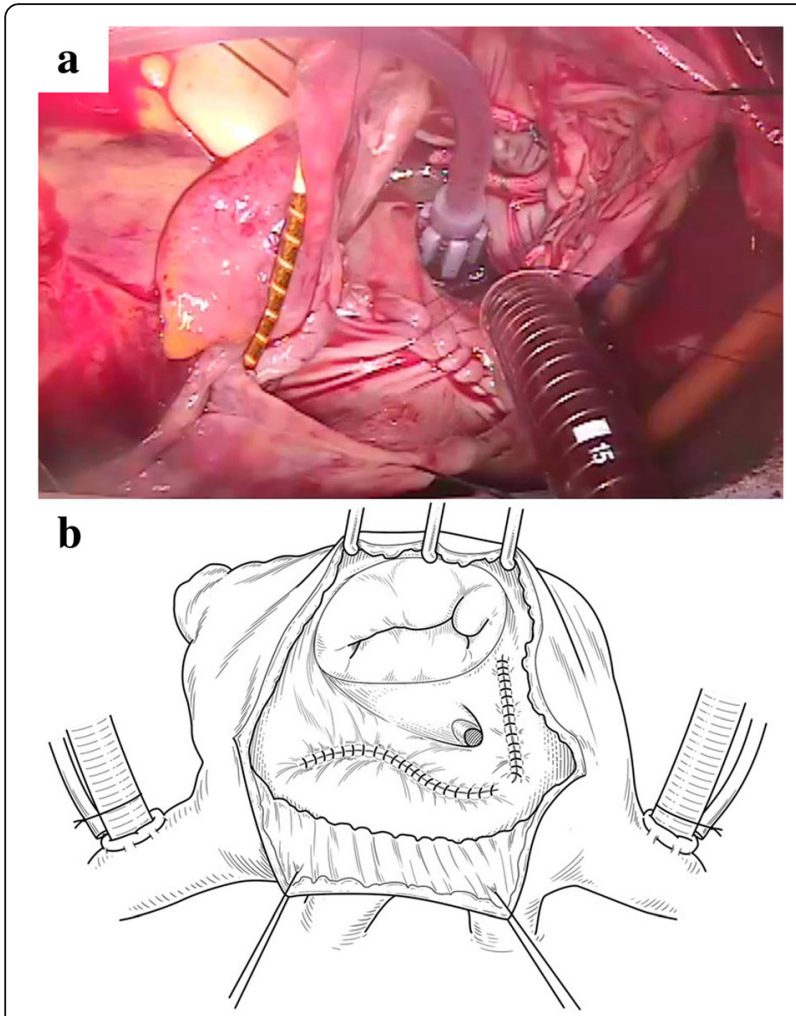

Fig. 4 a Intraoperative findings. Right atrium (RA) plication was performed at the interatrial septum and the space between the inferior vena cava and the tricuspid ring. $\mathbf{b}$ Intraoperative findings for RA inner side plication

can predict the postoperative outcome of TV surgery [6]. In our case, preoperative TAPSE remained within the normal range. However, postoperative TAPSE significantly decreased to $11.2 \mathrm{~mm}$ despite symptomatic improvement. If preoperative TAPSE is less than the normal range, TV surgery could decrease TAPSE further, resulting in a poor prognosis. TV surgery should be carried out early to avoid irreversible RV dysfunction with consideration for TAPSE.

Reduction atrioplasty is supposed to improve respiratory function by reducing RA volume and increasing tidal volume. Although the specific surgical technique for reduction atrioplasty was not described, Kalangos et al. reported reinforcement after partial resection by approximating and fixing the neighboring autologous pericardium to prevent the recurrence of dilatation [7]. In our patient, RA wall reinforcement with materials was not done, because the strength of the RA wall was sufficient after reduction atrioplasty.

Although left atrial was not enlarged, Maze procedure was not performed because of long-standing $A F$, very low fibrillatory wave amplitude, and irreversible RA function.

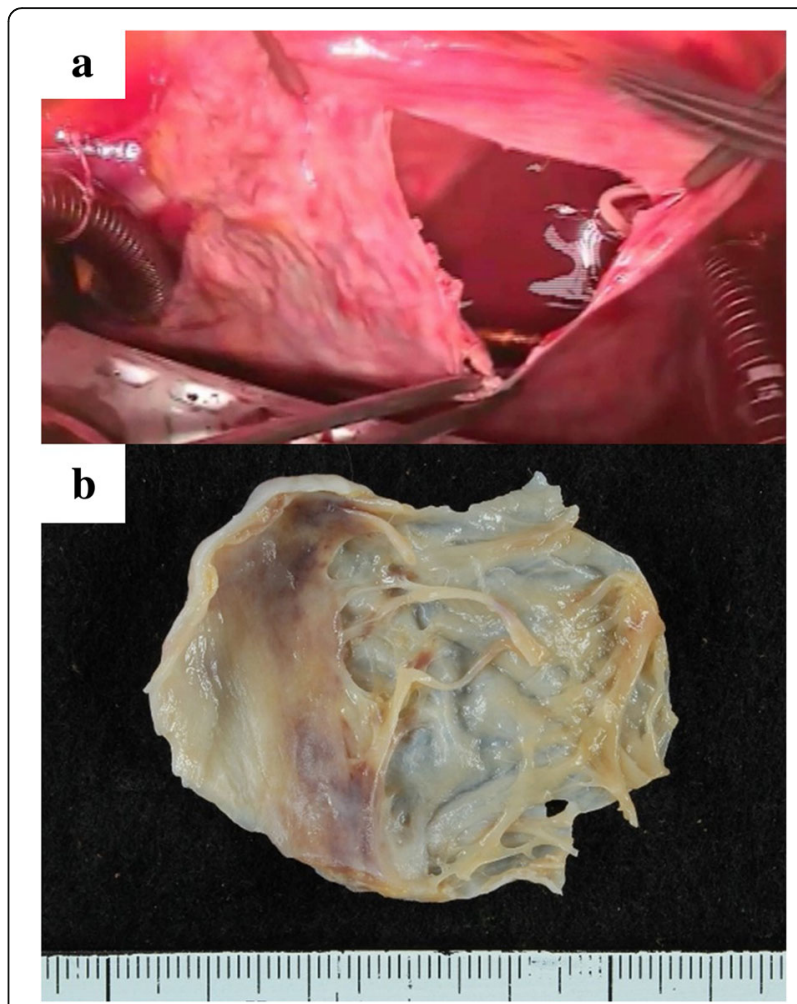

Fig. 5 a Photograph taken just after cutting of the right atrium (RA) wall during operation shows the extremely thin RA wall. $\mathbf{b}$ Tissue specimen of the resected free wall of the RA

\section{Conclusions}

A rare case of massive dilatation of the RA of unknown etiology is reported. Our operative procedure relieved the patient's symptoms and helped to prevent future complications, such as arrhythmia and left heart failure due to dilatation of the right ventricle.

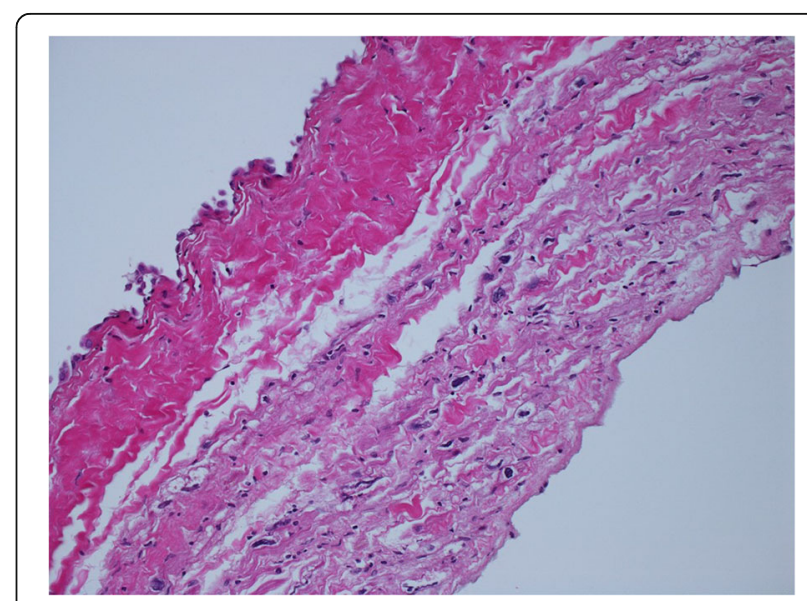

Fig. 6 Microscopic examination of tissue specimen from the right atrium (RA) wall showed thinning of the myocardium, inflammatory cell infiltrate, and few cardiomyocytes 


\section{Abbreviations}

AF: Atrial fibrillation; CT: Computed tomography; LV: Left ventricular; RA: Right atrium; RV: Right ventricular; TAPSE: Tricuspid annular plane systolic excursion; TR: Tricuspid regurgitation; TV: Tricuspid valve

\section{Acknowledgments}

The authors would like to thank Enago (www.enago.jp) for the English language review.

\section{Authors' contributions}

$\mathrm{MO}, \mathrm{HW}, \mathrm{KS}, \mathrm{YF}$, and KM participated in the discussion of the

pathophysiology and drafted the manuscript. MO and KM participated in the critical revision of the manuscript. All authors read and approved the final manuscript.

\section{Ethics approval and consent to participate}

Not applicable.

\section{Consent for publication}

The patient provided informed consent for the publication of this case report.

\section{Competing interests}

The authors declare that they have no competing interests.

\section{Publisher's Note}

Springer Nature remains neutral with regard to jurisdictional claims in published maps and institutional affiliations.

Received: 31 March 2018 Accepted: 21 June 2018

Published online: 03 July 2018

\section{References}

1. Srinivasa KH, Kharge J, Patil S, Rangan K, Ramalingam R, et al. Idiopathic dilatation of the right atrium: clinical and diagnostic pitfalls - a series of 3 cases. Echocardiography. 2013;30:984-8.

2. Binder $T M$, Rosenhek R, Frank H, Gwechenberger M, Maurer G, Baumgartner $\mathrm{H}$. Congenital malformations of the right atrium and the coronary sinus: an analysis based on 103 cases reported in the literature and two additional cases. Chest. 2000;117:1740-8.

3. Gomes $\mathrm{S}$, Wolfenden $\mathrm{H}$, Lambros J. Giant right atrium in an adult: case report of a rare condition. Heart Lung Circ. 2012;21:50-2.

4. Vahanian A, Alfieri O, Andreotti F, Antunes MJ, Barón-Esquivias G, Baumgartner $\mathrm{H}$, et al. Guidelines on the management of valvular heart disease (version 2012): the joint task force on the management of Valvular heart disease of the European Society of Cardiology (ESC) and the European Association for Cardio-Thoracic Surgery (EACTS). Eur J Cardiothorac Surg. 2012:42:S1-44.

5. Rudski LG, Lai WW, Afilalo J, Hua L, Handschumacher MD, Chandrasekaran K, et al. Guidelines for the echocardiographic assessment of the right heart in adults: a report from the American Society of Echocardiography endorsed by the European Association of Echocardiography, a registered branch of the European Society of Cardiology, and the Canadian Society of Echocardiography. J Am Soc Echocardiogr. 2010;23:685-713.

6. Sun X, Zhang H, Aike B, Yang S, Yang Z, Dong L, Wang F, et al. Tricuspid annular plane systolic excursion (TAPSE) can predict the outcome of isolated tricuspid valve surgery in patients with previous cardiac surgery? J Thorac Dis. 2016;8:369-74.

7. Kalangos A, Ouaknine R, Hulin S, Cohen L, Lecompte Y. Pericardial reinforcement after partial atrial resection in idiopathic enlargement of the right atrium. Ann Thorac Surg. 2001;71:737-8.

\section{Ready to submit your research? Choose BMC and benefit from:}

- fast, convenient online submission

- thorough peer review by experienced researchers in your field

- rapid publication on acceptance

- support for research data, including large and complex data types

- gold Open Access which fosters wider collaboration and increased citations

- maximum visibility for your research: over $100 \mathrm{M}$ website views per year

At BMC, research is always in progress.

Learn more biomedcentral.com/submissions 